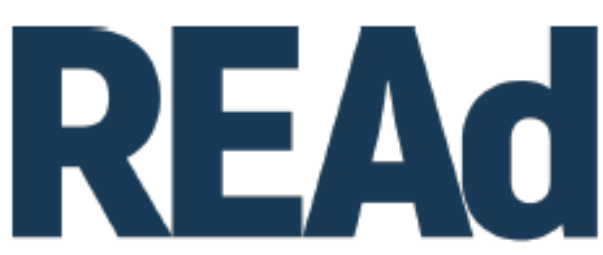

Revista Eletrônica de Administração

\title{
DISCUTINDO A ADEQUAÇÃO DAS ESCALAS DE MENSURAÇÃO DE VALORES AO CONTEXTO DAS INSTITUIÇÕES SEM FINS LUCRATIVOS: UMA ANÁLISE DO INVENTÁRIO DE PERFIS DE VALORES ORGANIZACIONAIS ${ }^{1}$
}

\author{
Sarah Santos Alves ${ }^{2}$ \\ Virgínia Donizete de Carvalho ${ }^{3}$
}

http://dx.doi.org/10.1590/1413-2311.301.101843

\section{RESUMO}

Com o objetivo de examinar as evidências de validade fatorial do Inventário de Perfis de Valores Organizacionais (IPVO) no contexto de instituições sem fins lucrativos, o estudo envolveu uma amostra de 203 respondentes, de 34 organizações. Os resultados da Análise Fatorial Confirmatória e do Escalonamento Multidimensional indicaram que a estrutura fatorial do IPVO foi apenas parcialmente confirmada, com a redução para seis dos oito fatores originais, além de algumas inconsistências na distribuição espacial dos valores. A testagem da nova estrutura para analisar a configuração hierárquica dos valores organizacionais nas instituições estudadas indicou certo grau de coerência dos resultados obtidos com a realidade em foco, a despeito das limitações do instrumento. O conjunto dos resultados conduz a ponderar que o IPVO apresenta um baixo nível de adequação para a análise dos valores organizacionais nesse contexto. As limitações da pesquisa e indicações para estudos futuros são apresentadas, especialmente no que tange à demanda pelo desenvolvimento de novas escalas ou pelo redesenho do IPVO, disponibilizando aos pesquisadores instrumentos nacionais para a

\footnotetext{
${ }^{1}$ Recebido em 10/4/2020, aceito em 22/11/2020.

${ }^{2}$ Universidade Presbiteriana Mackenzie. Programa de Pós-Graduação em Administração. São Paulo - SP (Brasil); http://orcid.org/0000-0001-7978-6592; sarahsadt@ yahoo.com.br.

${ }^{3}$ Universidade Federal de Alfenas. Programa de Pós-Graduação em Gestão Pública e Sociedade. Varginha - MG (Brasil); http://orcid.org/0000-0001-7929-0466; virginia.carvalho@unifal-mg.edu.br.
}

(c) (1) (9) REAd | Porto Alegre - Vol. 26 - N. 3 - Setembro / Dezembro 2020 - p. 739-764. 
mensuração de valores organizacionais que sejam aplicáveis em instituições de diferentes setores de atuação.

Palavras-chave: Valores organizacionais. Instrumentos de mensuração. Instituições sem fins lucrativos.

\section{DISCUSSING THE ADEQUACY OF THE VALUES MEASUREMENT SCALES IN THE CONTEXT OF NON-PROFIT INSTITUTIONS: AN ANALYSIS OF THE ORGANIZATIONAL VALUES PROFILES INVENTORY}

The aim of the study was to examine the evidence of factorial validity of the Organizational Values Profiles Inventory (IPVO) in the context of non-profit institutions, involving a sample of 203 respondents, from 34 organizations. The results of the Confirmatory Factor Analysis and Multidimensional Scaling indicated that the factorial structure of IPVO was only partially confirmed, with the reduction to six of the eight original factors, in addition to some inconsistencies in the spatial distribution of the values. The testing of the new structure to analyze the hierarchical configuration of organizational values in the institutions studied indicated a certain degree of consistency between the results obtained and the focused reality, despite the limitations of the instrument. The results leads to the consideration that IPVO has a low level of adequacy for the analysis of organizational values in this context. The limitations of the research and indications for future studies are presented, especially with regard to the demand for the development of new scales or for the redesign of the IPVO, providing researchers with national instruments for measuring organizational values that are applicable in institutions in different sectors of activity

Keywords: Organizational Values. Measurement Scales. Non-profit Institutions.

\section{DISCUTIENDO LA ADECUACIÓN DE LAS ESCALAS DE MEDIACIÓN DE VALORES AL CONTEXTO DE INSTITUCIONES SIN FINES DE LUCRO: UN ANÁLISIS DEL INVENTARIO DE PERFILES DE VALORES ORGANIZACIONALES}

Para examinar la evidencia de validez factorial del Inventario de Perfiles de Valores Organizacionales (IPVO) en el contexto de instituciones sin fines de lucro, el estudio incluyó una muestra de 203 encuestados, de 34 organizaciones. Los resultados del análisis factorial (c) (1) $\Theta$ REAd | Porto Alegre - Vol. 26 - ‥ 3 - Setembro / Dezembro 2020 - p. 739-764. 
confirmatorio y el escalado multidimensional indicaron que la estructura factorial de IPVO solo se confirmó parcialmente, con la reducción a seis de los ocho factores originales, además de algunas inconsistencias en la distribución espacial de los valores. La prueba de la nueva estructura para analizar la configuración jerárquica de los valores organizacionales en las instituciones estudiadas indicó un cierto grado de consistencia entre los resultados obtenidos y la realidad en foco, a pesar de las limitaciones del instrumento. El conjunto de resultados lleva a la consideración de que IPVO tiene un bajo nivel de adecuación para el análisis de valores organizacionales en este contexto. Se presentan las limitaciones de la investigación y las indicaciones para futuros estudios, especialmente con respecto a la demanda para el desarrollo de nuevas escalas o para el rediseño de la IPVO, proporcionando a los investigadores instrumentos nacionales para medir los valores organizacionales que son aplicables en instituciones en diferentes sectores de actividad.

Palabras clave: Valores organizacionales. Instrumentos de medida. Instituciones sin fines de lucro.

\section{INTRODUÇÃO}

A emergência das chamadas instituições sem fins lucrativos no país se deu no fim do século XX, principalmente entre os anos de 1960 e 1980, tendo experimentado uma expansão mais acelerada em seu número nas últimas décadas (INSTITUTO BRASILEIRO DE GEOGRAFIA E ESTATÍSTICA, 2012). No início dos anos 1990, por meio de mudanças na administração pública vindas de um argumento de sobrevivência à crise fiscal que se aprofundou entre os anos 1970 e 1980, foram abertos espaços para o crescimento do número de entidades dessa natureza, por intermédio de propostas descentralizadoras que incentivavam tanto a participação comunitária quanto a operacionalização dessas políticas por tais organizações (MONTAÑO, 2010).

Entretanto, por atuarem, normalmente, em condições instáveis de sustentabilidade econômica e sendo, em grande parte, dependentes de financiamentos externos, as instituições sem fins lucrativos tenderam a vivenciar certa perda de autonomia e até mesmo descaracterização de sua missão, haja vista a necessidade de preenchimento das exigências colocadas pelas instituições de fomento, privadas ou governamentais. Assim, vários estudiosos salientaram a ocorrência de uma mudança na orientação destas organizações ao longo do tempo (e. g. CERA, 2005; GOHN, 2003; MONTAÑO, 2010), destacando que transitaram de uma postura mais reivindicatória a outra mais parceira do Estado. 
Transcorridos alguns anos dessas publicações, cabe refletir a respeito de como se posicionam as prioridades axiológicas sustentadas pelas instituições sem fins lucrativos na atualidade, haja vista que os estudos sobre cultura e valores organizacionais nesse contexto são incipientes no Brasil, como já havia sido apontado por Nascimento et al (2016), em análise bibliométrica da produção nacional entre os anos de 2000 e 2013; tendo sido constatada manutenção dessa tendência no período subsequente àquele coberto pela revisão. A título de esclarecimento, vale informar que no cenário internacional, esse quadro não é muito diferente, com poucos estudos sobre o tema nas instituições sem fins lucrativos (e.g. CRAFT, 2018; HELMIG; HINZ; INGERFURTH, 2015; LEE, 2011; NEWTON; MAZUR, 2015), não obstante o fato de que se confrontam com crescentes demandas por eficiência (HELMIG; HINZ; INGERFURTH, 2015).

Uma discussão que tem sido empreendida no Brasil é de que há uma sub-representação de pesquisas empíricas que trabalhem as especificidades das instituições sem fins lucrativos, a qual, para alguns autores (e. g. PEREIRA et al., 2013; RAMOS; KLANN, 2015) é decorrente de sua heterogeneidade, da alta rotatividade dos seus trabalhadores e da desatualização das informações de registro disponíveis à população. Corroborando essa tese de sub-representação, Nascimento, Borges-Andrade e Porto (2016) apontam que, de modo geral, as pesquisas nacionais em comportamento organizacional, pouco têm se voltado ao universo do terceiro setor, comparativamente ao que se produz sobre organizações dos setores privado e público.

Os próprios instrumentos de mensuração em comportamento organizacional disponíveis na literatura nacional são construídos e testados, em sua maioria, visando ao contexto das instituições do setor privado, com alguns deles envolvendo organizações do setor público. Esse cenário contribui para que os estudiosos que contemplam as instituições sem fins lucrativos se vejam, muitas vezes, na contingência de ter que lançar mão de escalas desenvolvidas em contextos específicos, para mensurar fenômenos que, embora comuns a todas as organizações, carregam peculiaridades próprias a cada setor de atuação. Todavia, a adoção de tal estratégia tende a trazer o inconveniente, nem sempre considerado, de ocasionar a perda ou omissão de dados importantes em um trabalho de diagnóstico, dificultando que se mantenha a coerência entre os resultados obtidos e os pressupostos teóricos sob os quais as escalas costumam ser construídas.

É o que acontece, por exemplo, com os estudos sobre valores organizacionais (e.g. PAIVA; PEIXOTO; LUZ, 2014; ALVES; CARVALHO, 2019), para os quais se conta com uma série de instrumentos nacionais de mensuração (e.g. TAMAYO; GONDIM, 1996; TAMAYO; MENDES; PAZ, 2000; OLIVEIRA; TAMAYO, 2004; PORTO; FERREIRA, 
2017), nenhum deles, entretanto, construído ou testado com vistas à possibilidade de que sejam também aplicáveis junto a sujeitos atuantes em instituições sem fins lucrativos. Torna-se, portanto, pertinente questionar o seu nível de adequação para o propósito de levantamento e análise de dados na referida realidade, o que permanece, surpreendentemente, como uma problemática inexplorada nas pesquisas, não obstante sejam os valores cruciais na vida organizacional e centrais para a compreensão de sua cultura, liderança e desempenho (ZANDER; JONSEN; MOCKAITIS, 2016). Aliado a isso, tem-se o fato de que a pesquisa em valores organizacionais, de modo geral, tem sido tradicional e predominantemente operacionalizada por meio de levantamentos quantitativos (GIBB; BURNS, 2018), o que torna mais premente a necessidade de atenção à confiabilidade dos instrumentos utilizados para esse fim.

Dentre as escalas disponíveis na literatura nacional para a mensuração de valores, o Inventário de Perfis de Valores Organizacionais - IPVO (OLIVEIRA; TAMAYO, 2004) se destaca como um instrumento que tem sido utilizado em uma grande variedade de estudos (e.g. BEDANI, 2012; CÂMARA; PEREIRA-GUIZZO, 2015; CANOVA; PORTO, 2010; ESTIVALETE; ANDRADE, 2012; MELLO; SANT'ANNA, 2016; PAIVA, 2013; PAIVA; DUTRA, 2017; SILVA; OLIVEIRA, 2017). Foi adotado, inclusive, nas poucas pesquisas que contemplaram a temática dos valores junto a trabalhadores em instituições sem fins lucrativos (LOUBACK; TEIXEIRA; BIDO, 2009; PAIVA; PEIXOTO; LUZ, 2014; ALVES; CARVALHO, 2019), o que mostra a sua ampla aceitação e difusão no meio acadêmico nacional, justificando a sua escolha como o instrumento a ser analisado no presente estudo.

Importa salientar que no trabalho de Louback, Teixeira e Bido (2009), o qual examinou a relação entre valores organizacionais e racionalidades em organizações do terceiro setor, procedeu-se a uma adaptação semântica dos itens do IPVO e a um novo exame das evidências de sua validade, com a obtenção de uma estrutura fatorial que apresentou algumas diferenças em relação à original. Os autores teceram breves considerações sobre a necessidade de se atentar para a propriedade dos instrumentos utilizados em pesquisas de valores organizacionais no terceiro setor, mas também apontaram a fragilidade do material obtido após o processo de adaptação. Contudo, por se tratar de um estudo multicaso (que se restringiu a três organizações) e de uma versão adaptada do IPVO, não se debruçou em maiores considerações sobre o instrumento; o que não se constituía, de qualquer forma, como o objetivo do estudo. Permanece, portanto, aberto o questionamento quanto ao nível de adequação do IPVO para o levantamento de dados relativos aos valores organizacionais junto a instituições sem fins lucrativos. 
Atentando-se para essa lacuna, o presente trabalho elegeu como objetivo examinar as evidências de validade fatorial do Inventário de Perfis de Valores Organizacionais (IPVO) no contexto de instituições sem fins lucrativos, empregando uma amostra que contemplou 34 organizações atuantes em campos diversos, a saber: saúde, educação, assistência social, cultura e meio-ambiente. A partir da realização desse procedimento, empregou os dados levantados para analisar as prioridades axiológicas das entidades envolvidas no estudo, a partir da estrutura que emergiu após a análise fatorial confirmatória, ponderando sobre as limitações que o instrumento apresenta para o estudo da realidade em questão. São também apontadas demandas por pesquisas futuras que se dediquem, seja a uma reconstrução do IPVO, favorecendo sua aplicabilidade junto a instituições sem fins lucrativos, seja à criação de novos instrumentos, de caráter mais abrangente, que facilitem o levantamento de dados em organizações de diferentes setores de atuação, de modo a possibilitar, inclusive, o desenvolvimento de estudos comparativos.

\section{VALORES ORGANIZACIONAIS}

Os valores organizacionais são crenças compartilhadas a respeito de comportamentos desejáveis que conectam os membros de uma organização e orientam a construção da identidade organizacional, estando a serviço de interesses individuais, coletivos ou mistos, tendendo a apresentar um caráter de durabilidade ao longo do tempo, ainda que sejam passíveis de mudança (ADAMONIENĖ; RUIBYTE்; VIDUOLIENĖ, 2017; BOURNE; JENKINS, 2013; TAMAYO; GONDIM, 1996). Como elementos centrais da cultura da organização, os valores podem influenciar questões estratégicas, orientar o planejamento e os esforços organizacionais para atingir determinadas metas pretendidas e são normalmente associados a uma série de fenômenos organizacionais (BOURNE; JENKINS; PARRY, 2019; DERMOL; SIRCA, 2018; ÖZÇELIKA; AYBASB; UYARGILC, 2016). De acordo com Krajcsák (2018), quanto mais similares as atitudes e os sistemas de valores entre os membros da organização mais forte se torna a sua cultura.

Canova e Porto (2010, p. 11) salientam que "os valores organizacionais se tornaram um construto central nas ciências sociais e na compreensão dos fenômenos organizacionais, principalmente a partir da introdução do tema cultura organizacional no final da década de 1970”. Entretanto, de acordo com Bourne e Jenkins (2013), embora os pesquisadores tendam a conceber os valores organizacionais como entidades unitárias, completas e estáveis, uma análise cuidadosa do conceito permite constatar que eles podem assumir distintas formas de 
manifestação. Uma delas é a dos valores esposados, que são aqueles defendidos pelos fundadores e gestores da organização. Outra é a dos valores atribuídos, os quais são normalmente considerados como representativos da organização por parte de seus trabalhadores. Os valores compartilhados seriam aqueles obtidos quando se agregam os valores dos membros da organização. Já os valores desejáveis têm sua ênfase na intenção, em termos do que os empregados julgam que deveria ser a orientação organizacional (BOURNE; JENKINS; PARRY, 2019).

Dentre estas formas de manifestação, a que trata dos valores atribuídos tem sido a mais explorada nas pesquisas, embora haja estudos que foquem a congruência entre valores esposados e atribuídos (CRAFT, 2018), ou apenas os valores esposados (BOURNE; JENKINS; PARRY, 2019). São apresentados, inclusive, argumentos no sentido de que os valores atribuídos são os que melhor expressam, de fato, a orientação organizacional, pois se baseiam em padrões repetidos de comportamento e tem influência histórica sobre as ações e decisões institucionais (BOURNE; JENKINS; 2013; FOTAKI; LIOUKAS; VOUDOURIS, 2019). Por essa razão, alguns autores também os denominam como valores praticados (e.g. CRAFT, 2018; FOTAKI; LIOUKAS; VOUDOURIS, 2019), os quais podem ser acessados de maneira relativamente mais fácil, em virtude do fato de que os membros da organização podem indicar os valores praticados, mesmo que não compartilhem dos mesmos (BOURNE; JENKINS; 2013).

Quanto ao diagnóstico, irá variar em conformidade com a escolha do pesquisador em analisar valores esposados, atribuídos/praticados, compartilhados ou desejáveis. No Brasil, os estudos têm abordado, principalmente, três estratégias. Uma delas é a análise de documentos da organização, os quais expressem os valores esposados, ainda que sob a crítica de que este tipo de estratégia possa não alcançar a prática organizacional, mas apenas os comportamentos desejados pelos gestores. Outra estratégia consiste em utilizar uma média dos valores básicos dos trabalhadores como estimativa dos valores organizacionais, culminando na identificação dos chamados valores compartilhados, a qual também é criticada dadas as possíveis incongruências entre valores pessoais e organizacionais. A terceira e mais comum sugere o estudo de valores a partir da percepção dos empregados acerca dos valores efetivamente praticados na organização (valores atribuídos), abrangendo os comportamentos em diferentes níveis no cotidiano organizacional. Vale-se, normalmente, de levantamentos quantitativos realizados por meio de escalas de mensuração (OLIVEIRA; TAMAYO, 2004; TAMAYO; MENDES; PAZ, 2000). 
A construção e testagem de tais escalas tem sido objeto de estudos, nomeadamente por meio dos esforços de Tamayo e outros pesquisadores que com ele atuaram na construção de medidas como a Escala de Valores Organizacionais (EVO) (TAMAYO; GONDIM, 1996), o Inventário de Valores Organizacionais (IVO) (TAMAYO; MENDES; PAZ, 2000) e o Inventário de Perfis de Valores Organizacionais (IPVO) (OLIVEIRA; TAMAYO, 2004). Os dois últimos instrumentos guardam em comum o fato de se fundamentarem nos modelos de valores de Schwartz (1992; 1999) e, de acordo com Louback, Teixeira e Bido (2009, p. 231), apresentam "a vantagem de terem sido desenvolvidos considerando a realidade brasileira e basearem-se em uma teoria de valores propriamente dita". Isto também se aplicaria à nova Escala de Valores Organizacionais (PORTO; FERREIRA, 2017), construída e testada mais recentemente, com base em Schwartz (1999), num esforço de transpor algumas limitações identificadas no IVO.

No que tange ao desenvolvimento do IPVO, se deu mediante a constatação da necessidade de se ter instrumentos adequados que pudessem mensurar as raízes motivacionais de conflitos axiológicos nas organizações, abrindo novas perspectivas de análise da integração do indivíduo à organização e para a elaboração de estratégias e alternativas que diminuíssem os conflitos entre as metas individuais e organizacionais. Assim, seus autores o desenvolveram a partir da Teoria Motivacional de Valores Pessoais de Schwartz (1992), a qual apresenta, em sua versão original, uma estrutura composta por dez tipos motivacionais de valores pessoais, a saber: Autodeterminação, Estimulação, Hedonismo, Realização, Poder, Benevolência, Conformidade, Tradição, Segurança e Universalismo. Tais tipos motivacionais são agrupados em duas dimensões bipolares que estabelecem relações de oposição e adjacência, entre si, sendo assim denominadas: Abertura à mudança, Conservação, Autopromoção e Autotranscendência (SCHWARTZ, 1992).

O processo de construção e testagem do IPVO envolveu uma amostra composta por 833 trabalhadores de instituições de ensino de primeiro, segundo e terceiro graus privadas e públicas. O inventário utilizado foi constituído por 48 itens e seus resultados convergiram em oito fatores: Autonomia, Bem-estar, Realização, Domínio, Prestígio, Tradição, Conformidade e Preocupação com a coletividade (OLIVEIRA; TAMAYO, 2004). A hipótese de similaridade motivacional entre os valores pessoais e os valores organizacionais tanto no plano teórico quanto empírico foi confirmada pelos autores, com exceção do valor Segurança, que não significaria uma falta de simetria motivacional, mas uma deficiência na construção dos itens que pudessem representar este atributo. Já a respeito dos demais valores, houve correspondência direta entre os fatores organizacionais de Bem-estar, Realização, Tradição e Conformidade e as 
respectivas motivações em âmbito pessoal de Hedonismo, Realização, Tradição e Conformidade. Os fatores Prestígio e Domínio corresponderam às metas motivacionais do valor pessoal Poder. Os valores organizacionais e seus correspondentes no nível individual podem ser visualizados no Quadro 1, a seguir. Vale observar que a própria designação, pelos seus autores, das metas abrangidas por cada um dos valores já demonstra que o instrumento foi pensado de forma mais direcionada ao contexto de atuação das organizações do setor privado.

Quadro 1 - Valores organizacionais, correspondência com os Tipos Motivacionais de Valores e Metas dos Valores Organizacionais

\begin{tabular}{|c|c|c|}
\hline $\begin{array}{l}\text { VALORES } \\
\text { ORGANIZACIONAIS }\end{array}$ & $\begin{array}{l}\text { CORRESPONDÊNCIA COM } \\
\text { OS VALORES PESSOAIS }\end{array}$ & $\begin{array}{l}\text { METAS DOS VALORES } \\
\text { ORGANIZACIONAIS }\end{array}$ \\
\hline Autonomia & $\begin{array}{l}\text { Autodeterminação/ } \\
\text { Estimulação }\end{array}$ & $\begin{array}{l}\text { Oferecer desafios e variedade no trabalho, } \\
\text { estimular a curiosidade, a criatividade e a } \\
\text { inovação. }\end{array}$ \\
\hline Bem-estar & Hedonismo & $\begin{array}{l}\text { Promover a satisfação, o bem-estar e a } \\
\text { qualidade de vida no trabalho. }\end{array}$ \\
\hline Realização & Realização & $\begin{array}{l}\text { Valorizar a competência e o sucesso dos } \\
\text { trabalhadores. }\end{array}$ \\
\hline Domínio & Poder & $\begin{array}{l}\text { Obter lucros, ser competitiva e dominar o } \\
\text { mercado. }\end{array}$ \\
\hline Prestígio & Poder & $\begin{array}{l}\text { Ter prestígio, ser conhecida e admirada por } \\
\text { todos e oferecer produtos e serviços } \\
\text { satisfatórios para os clientes. }\end{array}$ \\
\hline Tradição & Tradição & $\begin{array}{l}\text { Manter a tradição e respeitar os costumes da } \\
\text { organização. }\end{array}$ \\
\hline Conformidade & Conformidade & $\begin{array}{l}\text { Promover a correção, a cortesia e as boas } \\
\text { maneiras no trabalho e o respeito às normas da } \\
\text { organização. }\end{array}$ \\
\hline $\begin{array}{l}\text { Preocupação com a } \\
\text { coletividade }\end{array}$ & Benevolência/ Universalismo & $\begin{array}{l}\text { Promover a justiça e a igualdade no trabalho } \\
\text { bem como a tolerância, sinceridade e } \\
\text { honestidade. }\end{array}$ \\
\hline
\end{tabular}

Fonte: OLIVEIRA; TAMAYO (2004). 
Ao encontrar simetria motivacional entre valores pessoais e organizacionais tanto no âmbito teórico quanto empírico, a criação desse questionário facilitou a verificação de congruências ou divergências nesses dois níveis de análise (OLIVEIRA; TAMAYO, 2004). Desse modo, conforme previamente mencionado, despontou como o instrumento de mensuração de valores mais adotado na literatura nacional, tendo sido empregado tanto com o objetivo de avaliar relações de conflito e/ou compatibilidade entre valores organizacionais e pessoais (ou do trabalho) (e.g. ALVES; CARVALHO, 2019; CÂMARA; PEREIRA-GUIZZO, 2015; MELLO; SANT'ANNA, 2016; PAIVA, 2013; PAIVA; PEIXOTO; LUZ, 2014), quanto em pesquisas que buscaram avaliar a relação dos valores organizacionais com outros construtos (e. g. BEDANI, 2012; CANOVA; PORTO, 2010; ESTIVALETE; ANDRADE, 2012; LOUBACK; TEIXEIRA; BIDO, 2009; SILVA; OLIVEIRA, 2017).

Alguns dos pesquisadores que o utilizaram, entretanto, relataram pequenos problemas quando realizaram novas testagens do instrumento junto às populações estudadas. É o caso de Canova e Porto (2010), cujo resultado obtido na realização de análise fatorial, com dados obtidos junto a docentes atuantes na educação básica de nível médio, não gerou o mesmo agrupamento de itens e número de fatores originais do IPVO, dado que Domínio, Prestígio e Realização se reuniram em um único fator e o mesmo ocorreu com Autonomia e Bem-estar, o que levou as referidas autoras a refletir sobre a possibilidade de que a estrutura original não se aplicasse a todos os tipos de organizações. Realizaram, ainda, escalonamento multidimensional (EMD), corroborando de maneira geral os pressupostos da teoria de valores de Schwartz (1992), por ter apresentado posicionamento condizente dos itens e tipos motivacionais. Constataram apenas a existência de espaços em branco no mapa do EMD, principalmente entre Domínio, Prestígio e Tradição, sinalizando sub-representação de tal conteúdo pelos itens do instrumento e sugerindo que pesquisas futuras revisassem o IPVO.

Outro caso foi o de Estivalete e Andrade (2012) que também encontraram diferenças na forma como se agruparam as variáveis e fatores em relação à estrutura original do IPVO. Segundo as autoras, embora tenham se mantido todos os valores apresentados na estrutura original de Oliveira e Tamayo (2004), alguns se uniram em um mesmo fator, ocasionando a junção de Autonomia e Realização e de Tradição e Conformidade. Uma ressalva foi por elas apresentada quanto a tal distinção na alocação das variáveis, dado que a despeito dessa diferenciação na estrutura, a coerência e o sentido dos fatores foram mantidos, já que Conformidade e Tradição compõem o polo Conservação e Autonomia e Realização, embora não compartilhem o mesmo polo, apresentam motivações adjacentes. Entretanto, considerando que os achados em estudos anteriores (como o de Canova e Porto, 2010) também apontaram a 
necessidade de agrupamentos que geraram estruturas distintas, sugerem que futuras pesquisas deveriam revisar o IPVO por meio de sua utilização em outras organizações ou realizarem análise fatorial confirmatória do mesmo (ESTIVALETE; ANDRADE, 2012).

\section{PROCEDIMENTOS METODOLÓGICOS}

A abordagem quantitativa foi utilizada nesta pesquisa por auxiliar no exame das evidências de validade de instrumentos de mensuração e na descrição de singularidades e opiniões por meio do uso de escalas (MARTINS; THEOPHILO, 2016). Para isso, foram realizados levantamentos, os quais abrangeram quatro áreas fundamentais do conteúdo, de acordo com Martins e Theophilo (2016), isto é, os dados pessoais dos respondentes, as informações comportamentais, as variáveis referentes ao ambiente de trabalho e, por fim, os dados acerca do nível de informações, das opiniões, intenção de comportamento, mensurações e expectativas.

A amostra não-probabilística por conveniência contou com a participação de 208 trabalhadores de 34 instituições sem fins lucrativos da mesorregião Sul/Sudoeste de Minas Gerais entre os meses de outubro de 2016 e março de 2017. A média de idade dos trabalhadores foi de 37 anos ( $D P=15,3$ anos), sendo $79 \%$ mulheres. A faixa de renda predominante se concentrou entre os trabalhadores que recebiam de 1 a 3 salários mínimos (51\%), seguidos por aqueles que recebiam de 4 a 5 salários (25\%). Quanto à escolaridade, $56 \%$ possuíam graduação (destes 26\% têm Pós-graduação). As principais áreas de atuação encontradas foram Educação $(39,9 \%)$, Saúde $(38,4 \%)$ e Assistência Social $(12,8 \%)$.

Para o levantamento dos dados foram utilizados dois instrumentos. A ficha sociodemográfica levantou dados referentes à idade, sexo, renda, escolaridade, situação de trabalho (trabalhador com remuneração, voluntário ou outro) e tempo de trabalho. O IPVO levantou informações acerca dos valores organizacionais, sendo composto por 48 itens que abordam diferentes situações cotidianas, com a pergunta: "Quanto esta organização aqui descrita se parece com aquela na qual você trabalha?". Para responder, o participante necessariamente precisa assinalar com um " $\mathrm{x}$ " a alternativa que melhor representa a realidade da organização em que trabalha, dentre as seguintes opções: se parece muito, se parece, se parece mais ou menos, se parece pouco, não se parece, não se parece nada.

A coleta dos dados foi realizada em dois momentos. No primeiro, foi realizada uma notificação anterior por telefone, e-mails e visitas in loco com gestores ou responsáveis pela comunicação externa nas organizações mapeadas nos três maiores municípios da referida 
mesorregião - Poços de Caldas, Pouso Alegre e Varginha -, informando-os a respeito do caráter voluntário da pesquisa, dos seus objetivos, do sigilo no tratamento dos dados e da contribuição deste estudo ao conhecimento organizacional, científico e social. Em um segundo momento, foi aplicado um formulário contendo a ficha sociodemográfica e o Inventário de Perfis de Valores Organizacionais (IPVO). Foram distribuídos, ao todo, 558 formulários, com uma taxa de retorno de $37 \%$. Após o processo de limpeza dos dados, foram retirados cinco questionários que continham mais de $15 \%$ de itens não respondidos, reduzindo o montante final de 208 para 203 formulários utilizáveis para as análises.

Para a condução dos procedimentos de análise dos dados em conformidade com os objetivos da pesquisa, foram realizados a Análise Fatorial Confirmatória (AFC) e o Escalonamento Multidimensional (EMD) do IPVO com vistas a testar a validade das variáveis latentes mensuradas. Outras análises como cálculos frequência, média, desvio padrão e teste Anova foram também utilizadas para desenhar o perfil dos respondentes e delinear as prioridades axiológicas das instituições estudadas, a partir da estrutura que emergiu após as análises. A AFC permite o teste das variáveis medidas e sua verificação quanto à qualidade de mensuração dos constructos. Já por meio do EMD é possível identificar dimensões-chave e, também, dimensões subjacentes usando uma série de julgamentos de similaridades fornecidos pelas respostas dos sujeitos participantes, contribuindo para avaliar suas percepções a respeito dessas dimensões (HAIR et al., 2009). As informações obtidas por meio da aplicação dos questionários foram registradas na forma de banco de dados do software de análise estatística SmartPLS, versão 3.0 M3 para a realização da AFC. O software de análise estatística SPSS versão 20 foi utilizado para o EMD, bem como para os cálculos de média, desvio padrão e testes Anova.

\section{RESULTADOS E DISCUSSÃO}

Para apresentação e discussão dos resultados, esta seção foi dividida em duas partes. Na primeira, foram examinadas as evidências de validade do IPVO no contexto de instituições sem fins lucrativos por meio de Análise Fatorial Confirmatória (AFC) e do Escalonamento Muldimensional (EMD) e, na segunda parte, foram analisados os resultados relativos às prioridades axiológicas das instituições pesquisadas a partir da nova estrutura fatorial obtida. 


\subsection{EXAMINANDO AS EVIDÊNCIAS DE VALIDADE DO INVENTÁRIO DE PERFIS DE VALORES ORGANIZACIONAIS EM SUA APLICAÇÃO JUNTO A INSTITUIÇÕES SEM FINS LUCRATIVOS}

Os resultados da AFC demonstraram que a estrutura fatorial original do IPVO foi apenas parcialmente confirmada no presente estudo. No que tange aos itens da escala, foram identificados e retirados cinco deles, por apresentarem baixas cargas fatoriais que estavam afetando a mensuração do IPVO, tendo em vista não atenderem a requisitos estatísticos mínimos, como o Alfa de Cronbach > 0,7, Confiabilidade Composta > 0,5 e Variância Média Extraída. O Alfa de Cronbach e a Confiabilidade composta são medidas de confiabilidade que variam de 0 a 1 , sendo os valores de 0,60 a 0,70 considerados o limite inferior de aceitabilidade e acima de 0,7 um valor bem visto na estatística para verificar a qualidade do construto proposto. Já a validade convergente avalia o grau em que duas ou mais medidas do mesmo construto se encontram correlacionadas. Assim, é possível dizer que há validade convergente quando a VME for superior a 0,5 (HAIR et al., 2009).

O primeiro item retirado foi "É importante para esta organização ser rica. Ela quer ter lucros nos negócios", referente ao valor organizacional Domínio. O segundo item retirado foi "Esta organização tem prestígio. Ela oferece produtos e serviços que são respeitados pelos clientes/cidadãos", o qual apresentou baixa contribuição na validação do valor organizacional Prestígio. O terceiro e quarto itens retirados pertencem ao valor Conformidade, são eles: “Esta organização acredita que a cortesia é importante. Para ela, as boas maneiras fazem parte do relacionamento entre os empregados e as organizações" e "Esta organização acredita que os empregados devem aceitar o trabalho que têm a fazer. Para ela, os empregados devem cumprir suas obrigações". O último item retirado foi "Esta organização evita mudanças. Ela prefere manter sua forma de trabalhar" referente ao valor organizacional Tradição.

Após a retirada desses itens, foi possível atender aos requisitos mínimos de validade discriminante e convergente dos fatores no nível dos itens. Apesar dos oito fatores alcançarem boas medidas de confiabilidade e de variância média extraída, os valores organizacionais de Autonomia, Realização e Bem-estar apresentaram correlação forte entre si, isto é, Autonomia e Realização ( $r=0,833)$, Autonomia e Bem-estar $(r=0,733)$ e Realização e Bem-estar $(r=0,68)$. Assim, optou-se por agrupar esses três valores organizacionais, após duas rodadas de análises, a primeira juntando apenas os valores de Autonomia e Realização e a segunda unindo os três valores organizacionais, atendendo aos requisitos estatísticos necessários. Durante o processo de agrupamento, percebeu-se que o valor Preocupação com a Coletividade também apresentou 
correlação forte com o novo agrupamento (ver Tabela 1). Apesar desse resultado, a ponderação por não incluir o fator Preocupação com a coletividade no novo fator agrupado se deu por este tratar de motivações divergentes, a respeito da promoção da igualdade e do altruísmo, enquanto Autonomia, Realização e Bem-estar se aproximam de uma preocupação com os próprios interesses.

Tabela 1 - Validade discriminante reunindo os fatores autonomia, realização e bem-estar

\begin{tabular}{|c|c|c|c|c|c|c|}
\hline & 1 & 2 & 3 & 4 & 5 & 6 \\
\hline 1. Autonomia + Realização + Bem-estar & 0,683 & & & & & \\
\hline 2. Conformidade & 0,552 & 0,652 & & & & \\
\hline 3. Domínio & 0,496 & 0,317 & 0,708 & & & \\
\hline 4. Preocupação com a coletividade & 0,748 & 0,485 & 0,220 & 0,741 & & \\
\hline 5. Prestígio & 0,436 & 0,587 & 0,328 & 0,429 & $\mathbf{0 , 7 7 3}$ & \\
\hline 6. Tradição & 0,375 & 0,494 & 0,366 & 0,320 & 0,592 & 0,752 \\
\hline Alfa de Cronbach & 0,935 & 0,663 & 0,771 & 0,859 & 0,666 & 0,735 \\
\hline Confiabilidade composta & 0,942 & 0,787 & 0,833 & 0,893 & 0,817 & 0,834 \\
\hline Variância Média Extraída (AVE) & 0,467 & 0,425 & 0,501 & 0,548 & 0,598 & 0,565 \\
\hline
\end{tabular}

Fonte: Dados da pesquisa

Assim, os resultados obtidos demonstram que a estrutura fatorial original do IPVO foi apenas parcialmente confirmada quando aplicado junto a instituições sem fins lucrativos, já que houve uma redução de oito para seis fatores. A despeito do fato de que análises realizadas em estudos anteriores também não encontraram os oito fatores originalmente propostos, os agrupamentos de fatores aqui realizados diferem daqueles empreendidos nas referidas pesquisas. Canova e Porto (2010), por exemplo, reuniram em mesmo fator os valores de Domínio, Prestígio e Realização e em outro os valores de Autonomia e Bem-estar. Já Estivalete e Andrade (2012) agruparam os valores de Autonomia e Realização em um fator e em outro os valores de Tradição e Conformidade. O único ponto comum entre os resultados da presente pesquisa e os dois referidos estudos reside no fato de que os valores de Autonomia e Realização não conseguiram se distinguir suficientemente para se constituir como um fator em nenhuma das análises, o que pode estar indicando, uma limitação geral do instrumento nesse aspecto, e não uma problemática que emerja especificamente quando é aplicado junto a instituições sem fins lucrativos.

De qualquer forma, com o intuito de obter uma visualização acerca da disposição espacial dos itens que permitisse ponderar com maior acerto quanto à propriedade do agrupamento de 
fatores indicado pelas análises até então empreendidas, foi realizado o EMD, seguindo as recomendações de Borg, Groenen e Mair (2013) de escolher o modelo PROXSCAL, com a matriz de proximidade por similaridade, de configuração inicial “Togerson” e um número mínimo de 1000 interações. Os resultados do EMD contribuíram no sentido de corroborar tanto a decisão de agrupamento dos fatores Autonomia, Realização e Bem-estar, quanto a opção por não incluir neste o fator Preocupação com a Coletividade, tendo em vista que apresentou uma concentração mais clara dos itens que o compõe (ver Figura 1).

Figura 1 - Escalonamento Multidimensional do IPVO

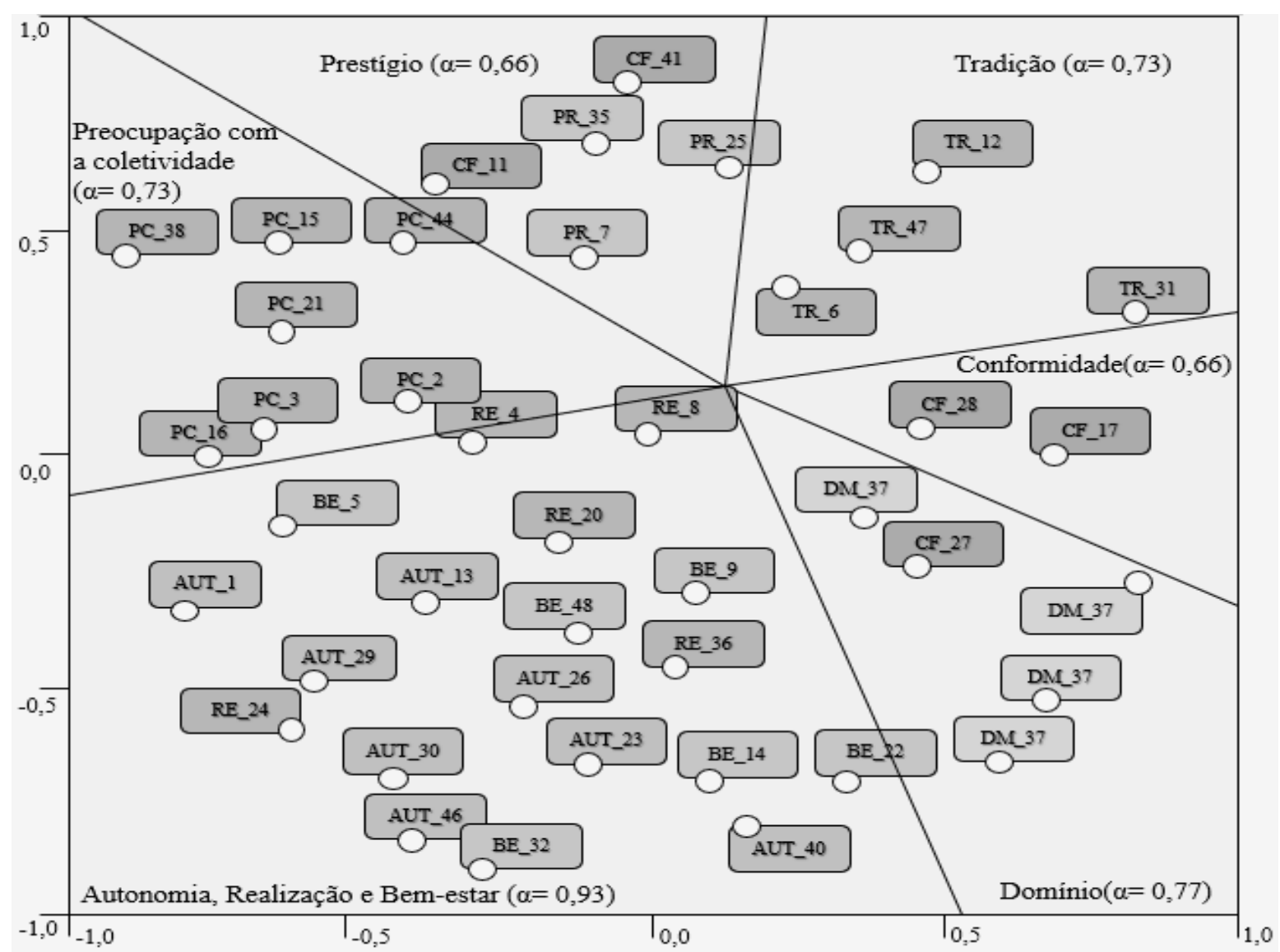

Fonte: Dados da pesquisa

Legenda: AUT=Autonomia / BE=Benevolência / CF=Conformidade / DM=Domínio / PC=Preocupação com a coletividade / PR=Prestígio / RE=Realização / TR=Tradição

A reunião de Autonomia, Realização e Bem-estar em um único fator, embora não seja a solução ideal, não chega a ser muito problemática, tendo em vista que o próprio Schwartz (1992) assinala a possibilidade de que valores adjacentes não apresentem clara distinção em seu posicionamento espacial, podendo vir a se misturar entre si. Todavia, na continuidade da 
observação dos resultados do EMD é possível notar alguns aspectos preocupantes quanto à distribuição espacial dos demais itens/fatores. Ao passo que no estudo de Canova e Porto (2010), o EMD apresentou evidências de confirmação dos pressupostos teóricos de Schwartz (1992) quanto à distribuição espacial dos itens/fatores, o mesmo não ocorreu no presente estudo. A figura 1 mostra que um dos pressupostos centrais da referida teoria não foi atendido, qual seja o do estabelecimento de uma relação de oposição esperada entre os valores de Prestígio e Preocupação com a Coletividade, uma vez que representam, respectivamente, os polos de Autopromoção e de Autotranscendência. O que os resultados estão sinalizando é que eles se posicionaram de forma adjacente, indicando compatibilidade e não conflito entre os mesmos.

A adjacência (ainda que teoricamente incoerente) entre os valores de Prestígio e Preocupação com a Coletividade poderia ser interpretada como um indicativo de que, nas instituições sem fins lucrativos, as metas motivacionais a respeito de reconhecimento e de admiração seriam compatíveis com a promoção de um ambiente de justiça e igualdade. Assim, tal proximidade entre os referidos valores sugeriria que, na percepção dos trabalhadores, a motivação que orienta o comportamento altruísta das pessoas nestas organizações estaria ocorrendo lado-a-lado com a tentativa de se obter certa notoriedade social pelo trabalho desenvolvido.

Outro dado preocupante e incoerente com a teoria de Schwartz (1992) é a oposição entre os valores de Domínio e Prestígio que se referem ao mesmo tipo motivacional (Poder) e que, portanto, deveriam estar posicionados de forma adjacente e não indicativa de conflito. Neste caso, a oposição entre os valores de Domínio e Prestígio poderia ser pensada em termos de que a obtenção de prestígio e reconhecimento social estaria caminhando na direção oposta da competitividade e domínio de mercado. Tais possibilidades de explicação, entretanto, se desenham a partir de um esforço de atribuir sentido aos resultados obtidos, dado o arranjo que se faz necessário ao se utilizar um instrumento desenhado principalmente para a realidade de empresas do setor privado junto a instituições sem fins lucrativos.

Tais esforços provavelmente não fossem necessários, caso o instrumento tivesse os seus itens reformulados no sentido de representar de maneira mais abrangente o conteúdo motivacional dos valores organizacionais, resgatando a meta central de cada tipo de valor, conforme previsto na teoria de Schwartz (1992). Assim, os valores de Domínio, por exemplo, não precisariam ser expressos exclusivamente em termos de eliminação da concorrência ou lucratividade, pois, corroborando o que foi assinalado na introdução, isso tende a acarretar a 
perda de informações importantes para o diagnóstico organizacional nas instituições sem fins lucrativos.

É possível, cogitar, inclusive que tais limitações na distribuição espacial dos itens representativos dos tipos motivacionais de valor não se repetissem e que seria possível alcançar a coerência com os pressupostos da teoria de valores de Schwartz (1992), caso o instrumento fosse revisado no sentido de alcançar maior abrangência no conteúdo expresso em seus itens. Em suma, o que os achados aqui obtidos mostram, de um modo geral, é que a adequação da versão original do IPVO para aplicação em instituições sem fins lucrativos se mostra baixa, podendo dar margem, inclusive à interpretação equivocada dos resultados, principalmente se os dados forem operacionalizados segundo a estrutura fatorial originalmente proposta.

\subsection{ANALISANDO AS PRIORIDADES AXIOLÓGICAS NAS INSTITUIÇÕES ESTUDADAS}

Após a realização dos ajustes na estrutura fatorial da escala e levando em consideração as limitações supramencionadas do instrumento para a mensuração de valores organizacionais em instituições sem fins lucrativos, empreendeu-se um exercício de buscar delinear uma hierarquia dos valores organizacionais que representasse as prioridades axiológicas das instituições estudadas, no intuito de avaliar o grau de razoabilidade dos resultados apurados. Procedeu-se, assim, aos cálculos de média e desvio padrão para cada fator do IPVO, bem como ao teste ANOVA de medidas repetidas para analisar a significância estatística da diferença entre as médias dos fatores (ver Tabela 2).

Tabela 2 - Hierarquia de Valores organizacionais nas organizações estudadas

\begin{tabular}{lcc}
\hline VALORES ORGANIZACIONAIS & MÉDIA & DESVIO PADRÃO \\
\hline Preocupação com a coletividade & 5,23 & 0,86 \\
Conformidade & 5,03 & 0,80 \\
Prestígio & 4,94 & 1,03 \\
& & 0,99 \\
Autonomia, Realização e Bem-estar & 4,41 & 1,04 \\
Tradição & 4,40 & 1,24 \\
& & 3,21 \\
\hline
\end{tabular}

Fonte: Dados da pesquisa 
Verificou-se que os valores de Preocupação com a Coletividade (correspondência com Autotranscendência) se posicionaram como os mais importantes para essas organizações, de acordo com a percepção de seus trabalhadores, o que apresenta coerência, tendo em vista o alinhamento de suas metas motivacionais com o objetivo dessas organizações de atuarem na promoção e defesa de direitos humanos como direito à saúde, à educação, à cultura, à ciência e tecnologia, ao desenvolvimento agrário e à assistência social, por exemplo. De acordo com Oliveira e Tamayo (2004, p. 137), "este fator é composto por valores que orientam o relacionamento cotidiano com indivíduos próximos e com a comunidade", o que descreve bem o tipo de orientação esperada por parte de instituições sem fins lucrativos, especialmente nos itens que abordam a justiça e a igualdade no tratamento das pessoas, bem como o respeito aos direitos e às oportunidades iguais.

Quanto aos valores organizacionais de Conformidade e Prestígio não se constatou diferença estatisticamente significativa entre suas médias, de modo que ocuparam conjuntamente a segunda posição dentre as prioridades axiológicas das instituições analisadas. No que tange à conformidade, este resultado é indicador de importância conferida à obediência aos superiores e também ao respeito às normas e regras, bem como aos modelos de comportamento considerados aceitáveis, seja no interior das próprias instituições ou em sua relação com o entorno. No que se refere ao Prestígio, cujos itens correspondem às metas motivacionais de Poder, salienta a valorização concedida ao reconhecimento e admiração social, bem como a capacidade de influência sobre o seu meio. Dado que Conformidade e Prestígio possuem metas motivacionais adjacentes, faz sentido que sejam valorizados na mesma medida.

O conjunto dos resultados referentes aos fatores Preocupação com a Coletividade, Conformidade e Prestígio, que emergiram entre os mais relevantes na orientação valorativa das organizações aqui estudadas, corrobora os achados de Louback, Teixeira e Bido (2009). Estes, ao buscar compreender a relação entre os valores organizacionais e as racionalidades em organizações do Terceiro Setor, também obtiveram escores relevantes para valores de Prestígio, Conformidade e Preocupação com a Coletividade, revelando, segundo eles, um perfil conservador muito semelhante ao da sociedade brasileira, no que se refere aos seus costumes e práticas.

Já quanto à média dos valores organizacionais de Autonomia, Realização e Bem-estar, as quais não se diferenciaram daquela atribuída ao valor Tradição, tem-se uma aproximação entre valores de Conservação, Autopromoção e Abertura à Mudança, que se mostra teoricamente incoerente. Isso porque sinaliza a valorização concomitante de metas motivacionais de (c) $\Theta$ REAd | Porto Alegre - Vol. 26 - N.o 3 - Setembro / Dezembro 2020 - p. 739-764. 
conteúdo oposto (Conservação x Abertura à Mudança). Em virtude, todavia, das limitações do IPVO para a mensuração de valores no contexto em questão e da fragilidade da estrutura fatorial que emergiu após a realização de análise fatorial confirmatória, não se tem parâmetros para discutir se esse resultado se deve a uma incoerência presente na própria realidade dessas organizações ou às deficiências do instrumento utilizado. E é nesse ponto, que começa a ficar mais claro como a adoção do IPVO, em sua versão original, para a mensuração de valores organizacionais em instituições sem fins lucrativos pode dificultar a boa qualidade de um diagnóstico.

Cabe discutir, ainda, no que se refere aos valores organizacionais de Autonomia, Realização e Bem-estar, que o fato de terem ocupado a penúltima posição na estrutura hierárquica axiológica dessas organizações pode encontrar duas explicações. A primeira estaria relacionada à própria redação dos itens que possuem aplicação limitada para a realidade das organizações sem fins lucrativos, como, por exemplo, "Nesta organização, os empregados são premiados. A satisfação deles com a organização é uma meta importante" ou "Para esta organização é importante manter clubes destinados ao lazer dos empregados. Ela considera que a diversão é uma parte importante para o empregado". Tal particularidade pode ter ocasionado que os respondentes atribuíssem baixos escores a estes itens, considerando que não descrevem a realidade de seu contexto laboral.

Entretanto, no estudo de Louback, Teixeira e Bido (2009) foi possível perceber que os valores organizacionais de Bem-estar, mesmo após adaptação de seus itens para atender às singularidades das instituições sem fins lucrativos, também obtiveram escores mais baixos. Isso conduz a outra possível explicação, a qual reafirmaria a pertinência dos resultados aqui encontrados, os quais seriam, então, sinalizadores de baixa preocupação quanto ao oferecimento de desafios e variedade no trabalho, valorização de competências individuais, bem como promoção de satisfação e qualidade de vida laboral, o que contribuiria para as discussões em torno das condições de trabalho em organizações sem fins lucrativos. Sob essa perspectiva, os trabalhadores estariam percebendo uma tendência à priorização de valores altruístas em relação à comunidade externa, ao preço da negligência quanto à autonomia, realização e bem-estar de seus membros internos. Conduta que pode estar refletindo o cenário brasileiro, o qual, de forma geral, tem apresentado condições de trabalho precárias no Terceiro Setor, com destaque à sobrecarga de trabalho e baixa remuneração, atenuadas por um discurso de solidariedade e altruísmo que envolve o setor.

No que concerne à baixa valorização do Domínio, que ocupou a última posição na hierarquia de valores das instituições analisadas, já se trata de um aspecto que empresta clareza 
e sentido aos resultados encontrados, dado que suas metas motivacionais estão centradas na competitividade e obtenção de status e controle sobre pessoas e recursos, tendo a questão dos lucros, presente em alguns de seus itens; o que destoa da característica altruísta e filantrópica presente no discurso das instituições sem fins lucrativos. Portanto, a pouca importância atribuída a valores dessa natureza mostra-se completamente coerente com o ideário que caracteriza a atuação das instituições sem fins lucrativos.

Por fim, tomando-se o conjunto dos resultados obtidos pode-se inferir, de modo geral, que predominam na orientação dessas organizações os valores relacionados à Autotranscendência (Preocupação com a Coletividade) e à Conservação (Conformidade) e Autopromoção (Prestígio), delineando um perfil de orientação voltada ao bem-estar e garantia de direitos da comunidade, aliado ao incentivo à obediência e honestidade nos procedimentos internos e externos, de forma que as pessoas que nelas trabalham e as demais organizações com as quais se relacionam sejam tratadas com base na verdade e em ações justas, sem deixar de lado as regras de convivência e os modelos de comportamento definidos socialmente como adequados, buscando, ainda que o benefício público que promovem possa ser admirado e tido como importante pelos cidadãos, com um apreço pela possível influência social que possam exercer.

Ao se considerar, contudo, a perda de dados ocasionada pela inexistência de itens que tratem de aspectos importantes para a realidade das instituições sem fins lucrativos e a inadequação de alguns dos itens existentes para o referido contexto de estudo, o IPVO falha em possibilitar aos pesquisadores um maior grau de confiança no momento de tecer conclusões, como ocorreu, por exemplo, com os resultados relativos à Tradição e à Autonomia, Realização e Bem-estar. Assim, embora os resultados por ele propiciados guardem certo grau de coerência com a realidade estudada, algumas inconsistências com os pressupostos teóricos em que se fundamenta (observadas tanto na estrutura fatorial obtida a partir da AFC, quanto em sua aplicação para análise das orientações valorativas das instituições), aliadas à baixa representatividade de seus itens para o contexto de estudo, o tornam um instrumento pouco apropriado para a realidade das instituições sem fins lucrativos, demandando cuidados redobrados nas análises e interpretações dos resultados, caso seja aplicado em sua versão original para a coleta de dados nesse contexto.

\section{CONSIDERAÇÕES FINAIS}


Os estudos sobre cultura e valores organizacionais no contexto das entidades sem fins lucrativos ainda são incipientes, tanto no Brasil quanto no exterior (NASCIMENTO et al., 2016; CRAFT, 2018; HELMIG; HINZ; INGERFURTH, 2015; LEE, 2011; NEWTON; MAZUR, 2015), não obstante a significativa contribuição das mesmas ao meio econômico e social de diferentes países. Esse problema se estende, no Brasil, à disponibilidade de medidas que sejam adequadas à avaliação das orientações valorativas predominantes nessas organizações, dado que os instrumentos de mensuração disponíveis na literatura nacional são construídos e testados visando, mormente, ao contexto das instituições do setor privado e, em alguns casos, envolvendo organizações do setor público. Tal problemática, embora possa trazer sérias repercussões sobre a qualidade da pesquisa junto às instituições sem fins lucrativos, tem sido pouco explorada na escassa literatura sobre o tema. Dessa forma, o presente trabalho se orientou pelo objetivo de examinar as evidências de validade fatorial de um dos instrumentos nacionais para a mensuração de valores organizacionais mais difundidos no meio acadêmico nacional (o IPVO), quando aplicado ao contexto de instituições sem fins lucrativos.

Empregando uma amostra que contemplou 34 organizações atuantes em campos diversos, o presente trabalho encontrou resultados que dão margem a algumas reflexões quanto ao seu nível de adequação para a mensuração de valores no contexto em questão. Primeiramente, os resultados da AFC demonstraram que a estrutura fatorial original do IPVO foi apenas parcialmente confirmada quando aplicado junto a instituições sem fins lucrativos, já que houve uma redução para seis dos oito fatores originais. A exemplo do que já havia ocorrido em outros estudos, que testaram o IPVO em diferentes contextos (CANOVA; PORTO, 2010; ESTIVALETE; ANDRADE, 2012), os valores de Autonomia e Realização não conseguiram se distinguir suficientemente para se constituir como um fator em nenhuma das análises, o que é indicativo de uma limitação geral do instrumento nesse aspecto. Entretanto, outras deficiências do IPVO emergiram quando testado junto a instituições sem fins lucrativos, algumas delas de caráter mais preocupante.

A primeira delas é de que além do agrupamento de valores de Autonomia e Realização, ainda se juntaram a eles os valores de Bem-estar, os quais também não se distinguiram como um fator. A outra, mais séria, concerne ao fato que a realização do EMD demonstrou que os valores estavam se distribuindo espacialmente de forma distinta daquela proposta na teoria de valores humanos de Schwartz (1992), que foi a base para o desenvolvimento do IPVO. Um dos pressupostos centrais da referida teoria, qual seja o do estabelecimento de uma relação de oposição entre os valores de Autopromoção (Prestígio) e Autotranscendência (Preocupação com a Coletividade), não foi atendido. Eles se posicionaram de forma adjacente, indicando 
compatibilidade e não conflito. Uma terceira deficiência, também referente a uma incoerência com a teoria de Schwartz (1992) foi a oposição observada entre os valores de Domínio e Prestígio, que se referem ao mesmo tipo motivacional (Poder) e que, portanto, deveriam estar posicionados de forma adjacente e não indicativa de conflito.

Na continuidade da avaliação da aplicabilidade do IPVO para o contexto de instituições sem fins lucrativos, procedeu-se a uma testagem da nova estrutura fatorial utilizando-a para analisar a configuração hierárquica dos valores organizacionais nas entidades estudadas. Os resultados apontaram certo grau de coerência com a realidade em foco, a despeito de outra inconsistência verificada, qual seja, a da valorização concomitante de elementos teoricamente antagônicos (Conservação X Abertura à Mudança). Observou-se, de modo geral, o predomínio dos valores de Autotranscendência (Preocupação com a Coletividade), seguidos por uma lógica de Conservação (Conformidade) e de Autopromoção (Prestígio). Aliados a esses resultados, a pouca expressividade conferida aos valores de Abertura à Mudança, contribuem para suscitar duas reflexões: a primeira diz respeito à viabilidade do próprio instrumento para caracterizar os valores em instituições sem fins lucrativos e a segunda concerne ao perfil de atuação social dessas organizações que tais prioridades axiológicas estariam contribuindo para elucidar, guardados os devidos cuidados, em virtude das deficiências do instrumento.

Tomando-se a primeira, é válido ponderar que o conjunto de resultados aqui obtidos fornecem algumas indicações de que o IPVO em sua versão original não se mostra um instrumento muito adequado para a mensuração de valores em instituições sem fins lucrativos. Aliado a tais resultados, a inexistência de itens no questionário que tratem de aspectos importantes para a realidade das instituições sem fins lucrativos e a inadequação de alguns dos itens existentes para o referido contexto de estudo, são suficientes para considerar que o IPVO não propicia aos pesquisadores desse campo uma medida de boa qualidade para a análise dos valores organizacionais, o que repercute na qualidade e confiabilidade do diagnóstico.

A segunda reflexão se constrói no sentido de ponderar que a configuração hierárquica dos valores organizacionais na presente pesquisa (resguardadas as suas limitações) seriam indicadores de que as instituições analisadas se caracterizam por uma postura mais avessa às transformações e quebras (pouca expressão aos valores de Abertura à Mudança), corroborando as argumentações de Fisher e Falconer (1998), Gohn (2003), Cera (2005) e Montaño (2010) de que houve uma mudança no comportamento das organizações sem fins lucrativos, a partir do início dos anos 1990, as quais passaram a atuar de modo menos contestatório e reivindicatório, principalmente pela necessidade de obtenção de recursos e pelas novas formas de parcerias com o Estado. Ademais, ao priorizar valores organizacionais de Conservação, os resultados desta 
pesquisa estariam em consonância com o discurso desses autores, reafirmando a inevitável atenção que se deve ter quanto à tendência de atribuição às instituições sem fins lucrativos de funções pertencentes previamente ao Estado, o qual tem se afastado paulatinamente de suas competências como provedor de serviços públicos voltados ao atendimento dos direitos dos cidadãos. Uma conduta mais conservadora por parte dessas instituições pode contribuir para a manutenção de um Estado mais afastado de suas responsabilidades sociais ao descentralizar esses serviços por intermédio de financiamento público, reafirmando um caráter assistencialista e, na maioria das vezes, preocupado com soluções emergenciais e de curto prazo de problemas na estrutura social.

Dadas, todavia, as limitações já salientadas do instrumento utilizado, aliadas às demais limitações do presente estudo, como o fato adotar amostragem não probabilística e ter acessado instituições atuantes em uma região específica de um único estado do país, o que não permite a generalização dos seus achados, fazem-se necessárias novas pesquisas sobre o tema em outras organizações dessa natureza, para que possam ser confirmadas as tendências que tais resultados parecem sinalizar. Reforça-se, também, a demanda por estudos futuros, seja para propor um redesenho dos itens do IPVO, criando uma nova versão da escala, que atenda também à realidade das organizações sem fins lucrativos, seja para a criação de novos instrumentos que possam facilitar o levantamento de informações sobre valores organizacionais praticados em instituições de diferentes setores de atuação, favorecendo, inclusive, a realização de estudos comparativos.

\section{REFERÊNCIAS}

ADAMONIENĖ, R.; RUIBYTĖ; L.; VIDUOLIENĖ, E. Organizational values: comparison of organizational features across different types of public sector organizations. Montenegrin Journal of Economics, v. 13, n. 4, p. 7-18, 2017. https://doi.org/10.14254/1800-5845/2017.13$\underline{4.1}$

ALVES; S. S.; CARVALHO, V. Relação entre valores pessoais e organizacionais em instituições sem fins lucrativos. In: Seminários em Administração, 22., 2019, São Paulo. Anais... São Paulo: XXII SEMEAD, 2019

BEDANI, M. O impacto dos valores organizacionais na percepção de estímulos e barreiras à criatividade no ambiente de trabalho. Revista de Administração Mackenzie, v. 13, n. 3, 2012. https://doi.org/10.1590/S1678-69712012000300008

BORG, I.; GROENEN, P. J. F.; MAIR, P. Applied multidimensional scaling. New York:Springer, 2013. 
BOURNE; H.; JENKINS, M. Organizational values: a dynamic perspective. Organization Studies, v. 34, n. 4, p. 495-514, 2013. https://doi.org/10.1177/0170840612467155

BOURNE; H.; JENKINS, M.; PARRY, E. Mapping espoused organizational values. Journal of Business Ethics, v. 159, p. 133-148, 2019. https://doi.org/10.1007/s10551-017-3734-9

CÂMARA, J. R. S.; PEREIRA-GUIZZO, C. S. Work-related values and organizational values from the perspective of university professors: A correlational study. Estudos de Psicologia, v. 32, n. 2, p. 259-268, 2015. http://dx.doi.org/10.1590/0103$\underline{166 X 2015000200010}$

CANOVA, K. R.; PORTO, J. B. O impacto dos valores organizacionais no estresse ocupacional: um estudo com professores de ensino médio. Revista de Administração Mackenzie, São Paulo, v. 11, n. 5, p. 4-31, 2010. https://doi.org/10.1590/S1678$\underline{69712010000500002}$

CERA, F. L. B. Terceiro Setor e biopolítica: as organizações diante da sociedade de massas. Revista de Ciências da Administração, Santa Catarina, v.7, n.14, 2005.

https://doi.org/10.5007/\%25x

CRAFT, J. L. Common thread: The impact of mission on ethical business culture. Journal of Business Ethics, v. 149, n. 1, p. 127-145, 2018. https://doi.org/10.1007/s10551-016-3034-9

DERMOL, V.; SIRCA, N. T. Communication, company mission, organizational values, and company performance. Procedia - Social and Behavioral Sciences, v. 238, p. 542-551, 2018. https://doi.org/10.1016/j.sbspro.2018.04.034

ESTIVALETE, V. F. B.; ANDRADE, T. A influência dos valores organizacionais na percepção de suporte organizacional com base na concepção dos colaboradores do setor bancário. Revista de Administração Mackenzie, v. 13, n. 3, p. 214-24, 2012. https://doi.org/10.1590/S1678-69712012000300010

FOTAKI, M.; LIOUKAS, S.; VOUDOURIS, I. Ethos is destiny: organizational values and compliance in corporate governance. Journal of Business Ethics, Feb., 2019. https://doi.org/10.1007/s10551-019-04126-7

GIBB, S.; BURNS, C. Organizational values: positive, ambivalent and negative interrelations in work organizations. Journal of Human Values, v. 24, n. 2, p. 116-126, 2018. https://doi.org/10.1177/0971685818754894

GOHN, M. da G. Os sem-terra, ONGs e cidadania: a sociedade civil brasileira na era da globalização. 3. ed. São Paulo: Cortez, 2003.

HAIR JR., J. F. et al. Análise multivariada de dados. 6. ed. Porto Alegre: Bookman, 2009.

HELMIG, B.; HINZ, V.; INGERFURTH, S. Valuing organizational values: assessing the uniqueness of nonprofit values. Voluntas, v. 26, p. 2554-2580, 2015.

https://doi.org/10.1007/s11266-014-9530-6 
INSTITUTO BRASILEIRO DE GEOGRAFIA E ESTATISTICA. As fundações privadas $e$ associações sem fins lucrativos no Brasil 2010. Rio de Janeiro, 2012.

KRAJCSÁK, Z. Making high committed workplaces by strong organizational values. Journal of Human Values, v. 24, n. 2, p. 127-137, 2018. https://doi.org/10.1177/0971685818764064

LOUBACK, J.; TEIXEIRA, M. L. M.; BIDO, D. S. Valores organizacionais e racionalidades: uma visita ao Terceiro Setor. Organizações \& Sociedade, v. 16, n. 49, p. 225-246, 2009. https://doi.org/10.1590/S1984-92302009000200002

MACÊDO, K. B. et al. Valores individuais e organizacionais: estudo com dirigentes de organizações pública, privada e cooperativa em Goiás. Cadernos de Psicologia Social do Trabalho, v. 8, p. 29-42, 2005. https://doi.org/10.11606/issn.1981-0490.v8i0p29-42

MARTINS, G. A.; THEÓPHILO, C. R. Metodologia da investigação científica para ciências sociais aplicadas. 3. ed. São Paulo: Atlas, 2016.

MELLO, A. M. G.; SANT'ANNA, A. S. Valores pessoais e organizacionais em diferentes grupamentos geracionais. Revista Ciências Administrativas, v.22, n. 1, p. 255-282, 2016. http://dx.doi.org/10.5020/2318-0722.2016.v22n1p255

MONTAÑO, C. Terceiro Setor e questão social: crítica ao padrão emergente de intervenção social. 6. ed. São Paulo: Cortez, 2010.

NASCIMENTO, T. G. et al. Valores organizacionais: uma análise bibliométrica da produção nacional do período de 2000 a 2013 na área de administração. Organizações em Contexto, v. 12, n. 24, 2016. http://dx.doi.org/10.15603/1982-8756/roc.v12n24p37-64

NASCIMENTO, T. T.; BORGES-ANDRADE, J. E.; PORTO, J. B. Produção científica brasileira sobre comportamento organizacional no Terceiro Setor. Estudos de Psicologia, Campinas, v. 33, n. 2, p. 367-374, 2016. https://doi.org/10.1590/1982-02752016000200018

OLIVEIRA, A. de F.; TAMAYO, A. Inventário de perfis de valores organizacionais. Revista de Administração - USP, v. 39, n. 2, p. 129-140, 2004.

ÖZÇELIKA, G.; AYBASB, M.; UYARGILC, C. High performance work systems and organizational values: resource-based view considerations. Procedia - Social and Behavioral Sciences, v. 235, p. 332-341, 2016. https://doi.org/10.1016/j.sbspro.2016.11.040

PAIVA, K. C. M. Valores organizacionais e do trabalho: um estudo com jovens trabalhadores brasileiros. Tourism and Management Studies, v. 9, n. 2, p. 100-106, 2013.

PAIVA; K. C. M.; DUTRA, M. R. S. Valores organizacionais e valores do trabalho: um estudo com operadores de call center. Cadernos EBAPE.BR, v .15, n. 1, 2017. http://dx.doi.org/10.1590/1679-395153725

PAIVA, K. C. M. PEIXOTO, A. F.; LUZ, T. R. Valores organizacionais e do trabalho: um estudo com professores de uma escola filantrópica e confessional de Belo Horizonte (MG). RECADM, v. 13, n. 1, p. 89-113, 2014. http://dx.doi.org/10.5329/RECADM.2014005 
PEREIRA, R. da $S$. et al. Especificidades da gestão no Terceiro Setor. Organizações em Contexto, v. 9, n. 18, p. 167-195, jul./dez. 2013. http://dx.doi.org/10.15603/1982-

8756/roc.v9n18p167-195

PORTO; J. B.; FERREIRA, M. C. Uma Escala de Valores Organizacionais com base na Teoria de Valores Culturais de Schwartz. Psicologia: Teoria e Pesquisa, v. 32 n. esp., p. 1-10, 2017. http://dx.doi.org/10.1590/0102-3772e32ne222

RAMOS, F. M.; KLANN, R. C. Qualidade da informação contábil das entidades brasileiras do Terceiro Setor. Future Studies Research Journal, v. 7, n. 1. p. 3-32, 2015.

https://doi.org/10.7444/fsrj.v7i1.177

SCHWARTZ, S. H. (1992). Universals in the content and structure of values: theory and empirical tests in 20 countries. In: ZANNA, M. (ed.) Advances in experimental social psychology. New York: Academic Press, v. 25, 1-65, 1992.

SCHWARTZ, S. H. Cultural value differences: Some implications for work. Applied Psychology: An International Review, n. 48, p. 23-47, 1999.

SILVA, U. L.; OLIVEIRA, A. F. Qualidade de vida e valores nas organizações: impactos na confiança do empregado. Psicologia: Ciência e Profissão, v. 37 n. 1, p. 7-17, 2017. https://doi.org/10.1590/1982-3703000012015

TAMAYO, A.; GONDIM, M. G. C. Escala de valores organizacionais. Revista de Administração (USP), v. 31, n. 2, p. 62-72, 1996.

TAMAYO, A.; MENDES, A. M; PAZ, M. G. T. Inventário de valores organizacionais. Revista Estudos de Psicologia, Natal, v. 5, n. 2, p. 289-317, 2000.

https://doi.org/10.1590/S1413-294X2000000200002

ZANDER, L.; JONSEN, K.; MOCKAITIS, A. I. Leveraging values in global organizations: Premises, paradoxes and progress. Management International Review, v. 56, n. 2, p. 149-169, 2016. https://doi.org/10.1007/s11575-015-0277-0 